\title{
Mechanical Properties of a Novel Plastic Hinge Seismic Fuse Based on Frictional Energy Dissipation to Avoid Brittle Failures in Beam-to-Column Moment-Resistant Joints
}

\author{
Xiaodong $\mathrm{Li}^{1} \cdot$ Qitai Wang $^{1}$ (D) Guangtian $\mathrm{Ma}^{1}$
}

Received: 1 July 2019 / Accepted: 22 October 2019 / Published online: 29 October 2019

(C) The Author(s) 2019

\begin{abstract}
Traditional steel structure joints are prone to brittle failure under seismic excitation, and it is difficult to precisely control the location of the resulting plastic hinge or repair these joints after an earthquake. Therefore, based on the energy dissipation principle of the friction pendulum isolation bearing and automobile braking device, a low-cost friction-based plastic hinge $(\mathrm{PH})$ joint is proposed to provide predictable energy dissipation and realize quickly repairable structures. The proposed $\mathrm{PH}$ was analysed theoretically, and five half-scale specimens using different bolt and friction materials were tested using cyclic reversing load. The test results showed that models PH-1 and PH-2 with Grade 4.8 and 8.8 limiting bolts, respectively, both provided a plastic rotation angle greater than $0.03 \mathrm{rad}$, exhibited experimental moment capacities of 0.91 and 0.93 times their theoretical capacities, and exhibited ductility coefficients of 2.75 and 3.14, respectively. It was found that high-strength limiting bolts were unsuitable as they damaged difficult-to-replace PH components. The selected PH configuration experienced damage to only the limiting bolts and friction plates and exhibited good plastic deformation capacity and hysteretic energy dissipation performance that met the plastic rotation, ductility, and friction energy dissipation requirements. Thus, the proposed PH can be used to improve the seismic performance of beam-to-column joints and the frames they form.
\end{abstract}

Keywords Friction energy dissipation $\cdot$ Plastic hinge $\cdot$ Mechanical properties $\cdot$ Seismic performance $\cdot$ Ductility

\section{Introduction}

Ever since large area brittle failures of beam-to-column joints were observed following the 1994 Northridge earthquake in California, USA, and the 1995 Kobe earthquake in Japan, many scholars have conducted experimental and theoretical studies on the seismic and ductile properties of beam-to-column joints in steel structures [1-6]. The results of these studies indicate that an effective way to prevent the brittle failure of beam-to-column joints is to move the plastic hinges out of the columns. At present, the

Qitai Wang

qitai_wang@163.com

Xiaodong Li

xdli@lut.cn

Guangtian Ma

maguangtai2019@163.com

1 School of Civil Engineering, Lanzhou University of Technology, Lanzhou 730050, China main form of realizing such plastic hinge displacement is to strengthen the end of the beam or to weaken a section of the beam; that is, to relatively strengthen the beam-tocolumn joint so that the hinge forms in the beam and not the joint. Marante et al. [7] and others [8, 9] analysed the seismic behaviour of plastic hinges in a frame structure to derive a theory describing the formation of plastic hinges. It has been determined through cyclic loading tests that the load capacity, stiffness, and hysteretic energy dissipation of steel frames were improved when using steel beamreinforced joints, which moved the plastic hinge out of the column [6, 10, 11]. Oh et al. [12] evaluated the seismic behaviour of a basic weak-axis column-tree connection frequently used in steel moment-resisting frames in Korea. Lee and Yoo [13] and Lee et al. [14] showed that the flanges of beams have little effect on the development of the post-buckling strength of the web panels, and that the shear resistance of the flanges is the main cause of the small difference in the shear capacities of beams rather than the flexural rigidity of the flanges. Research into the plastic hinges of steel structures conducted in China 
weakened or strengthened the sections of a steel beam so that the plastic hinge moved out from the column body during a strong earthquake, preventing the brittle failure of the structure [15-19]. Llanes-Tizoc et al. [20] and others [21,22] studied the ductility of different steel structure components and explored the influence of ductility on the overall seismic performance of the structure. It has also been observed that specimens with strong columns and weak beams can better engage the plastic load capacity of the beam and form a beam hinge failure mechanism, so that they exhibit large deformation and energy dissipation capacities; that is, good seismic performance [23-25]. Kanyilmaz et al. [26-28] and Dougka et al. [29] applied the concept of seismic fuse to beam-to-column joints to solve the above problems. The fuses system takes into account the strength, stiffness, and ductility of the joints. It is easy to repair or replace after the earthquake.

Although current relevant research has effectively achieved the relocation of the plastic hinge outside of the column to sufficiently ensure the integrity of beam-to-column joints, it remains difficult to control energy dissipation during an earthquake and the resulting irreparable damage to frame structures. Therefore, based on the current state of research into the plastic hinges of steel structures, this paper proposes a novel friction-based plastic hinge $(\mathrm{PH})$ joint and evaluates its ability to improve the ductility of the structure that contains it, realizing the precise control of structural energy dissipation and achieving the seismic performance target of being "large earthquake repairable". Accordingly, the failure mode, ultimate load capacity, joint ductility, hysteresis, and other mechanical properties of five variants of the proposed novel friction-based $\mathrm{PH}$ joint were studied at half-scale with the results presented in this paper.

\section{Materials and Methods}

\subsection{Design Principle}

A novel friction-based $\mathrm{PH}$ joint was designed based on the energy dissipation principle of the friction pendulum isolation bearing and automobile brake device $[30,31]$ that can be widely applied to steel truss and steel frame structures. When minor and moderate earthquakes occur, the plastic hinge joint remains in the elastic range of the member and acts as a rigid joint. When a major earthquake occurs, some members of the structure will lose their ability to carry load due to shear failure, leading to the emergence of a lateral displacement angle between frame stories. At this time, the $\mathrm{PH}$ joints will transition from rigid connections to semi-rigid connections and dissipate friction energy as a result of the relative rotation between connected members.

\subsection{Model Construction}

The proposed PH joint consists of a rotating element, a fixed element, and a connection energy dissipation unit. The basic structure of the proposed PH joint is shown in Fig. 1a [32]. The rotating element mainly consists of a steel beam, a circular arc sealing plate welded to a single connection plate (which can be sandblasted), and bolt holes, as shown in Fig. 1b. The fixed element mainly consists of a steel beam, circular tube sealing plate, and limiting strips, as shown in Fig. 1c. The connection energy dissipation unit mainly consists of double connection plates, double friction plates, a loading rotary bolt, and limiting bolts, as shown in Fig. 1d-f. In this design, the circular arc sealing plate and circular tube sealing plate are, respectively, welded to the steel beams on the left and right sides. The limiting strips are uniformly arranged around the inside of the circular tube sealing plate (with a groove for the single connection plate in the centre of the connection) to prevent rotation of the double connection plates, as can be seen in Fig. 1c. The double friction plates are set on the insides of the double connection plates and are compressed by the loading rotary bolt. The limiting bolts provide the initial strength and serve as the main energy consuming components, as shown in Fig. 1e. As can be seen in Fig. 1d, f, the double connection plates and friction plates are similar in structure, and both are equipped with limiting grooves and bolt holes matching those on the circular tube sealing plate.

\subsection{Theoretical Analysis}

The proposed friction-based PH joint was applied to a structural system according to its working principle based on the study of the lateral stiffness of steel frame structures [33, 34]. The PH was arranged in the structural system such that the sections of the columns connected to the beams and the beams connected to the PH could be considered rigid domains. The friction-based $\mathrm{PH}$ was designed to apply a prestress to the double connection plates via the loading rotary bolt to ensure that the joint acts using two friction plates but only a single connection plate. When the structure is subjected to horizontal and vertical loads, the lateral displacement of the column under horizontal loads changes from elastic deformation to plastic deformation and the accompanying rotation dissipates energy in the form of friction in the PH. In this section, the elastic limit of rotation and associated yield moment of the $\mathrm{PH}$ are derived, and the friction energy dissipation of the $\mathrm{PH}$ is quantified based on its parameters. 
Fig. 1 Proposed novel frictionbased plastic hinge (PH) joint (units in $\mathrm{mm}$ ): a the assembled $\mathrm{PH} ;$ b rotating element; $\mathbf{c}$ fixed element; $\mathbf{d}$ double connection plates; e position of the friction plates in the double connection plates; f friction plates

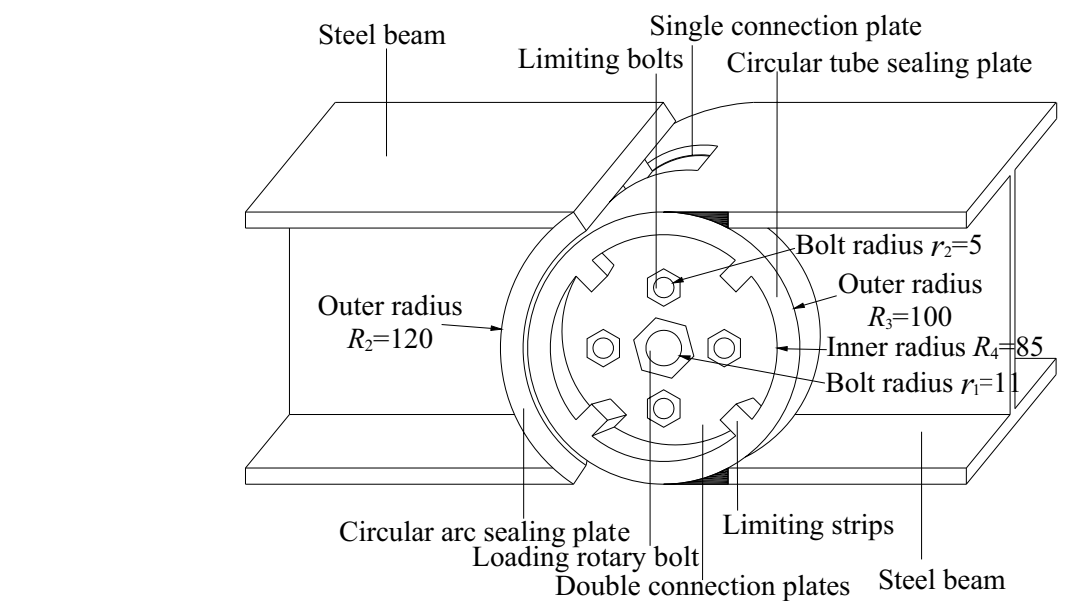

(a)

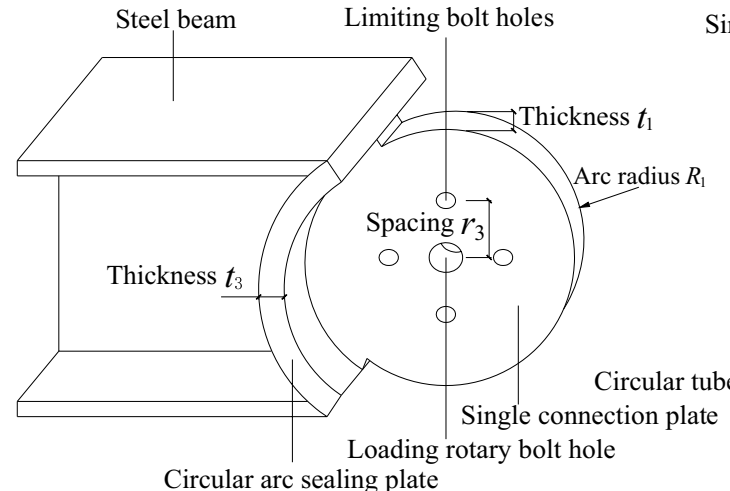

(b)
Single connection plate groove

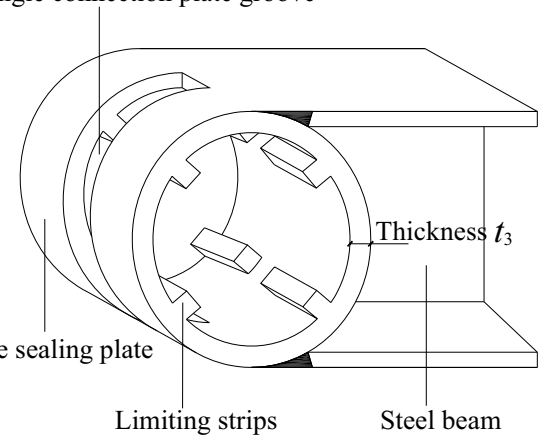

(c)
Friction plates . Friction plates

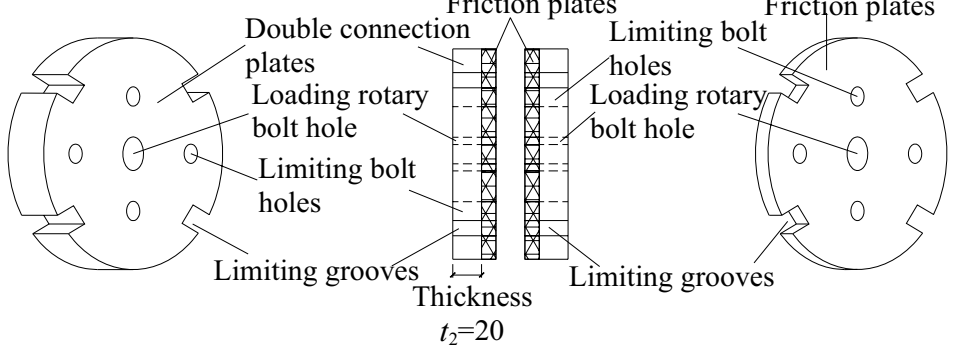

(d)

(e)

(f)

\subsubsection{Inter-storey Drift Angle Theory}

According to the principle of superposition, when a structural system is subjected to a horizontal load $F_{i}$ and vertical uniformly distributed load $q$, an inter-storey drift angle, $\theta_{1}$, occurs in the structure, as shown in Fig. 2. As the structural system displaces sideways under $F_{i}$, the end of the steel beam will bend at an angle relative to the column vertical direction, the horizontal lateral stiffness of the structure will decrease, and the beam segments on each side of the $\mathrm{PH}$ joint will rotate around the loading rotary bolt. In this study, the relative rotation angle $\theta_{2}$ at the beam-to-column connection end is used in place of inter-storey drift angle $\theta_{1}$ and can be approximately expressed as the ratio of the beam end displacement to the beam length, based on Fig. 2, and is given by:

$\theta_{1}=\theta_{2}=\frac{L_{3}}{L_{2}}$

where $L_{2}$ and $L_{3}$ are the distance (beam length) from the free end of the beam to the rotation point and the displacement of the free end of the beam, respectively.

\subsubsection{Calculation of Load Capacity of PH Joint Domain}

Using H-shaped beam components in these experiments, based on the plastic properties of the steel material and the 


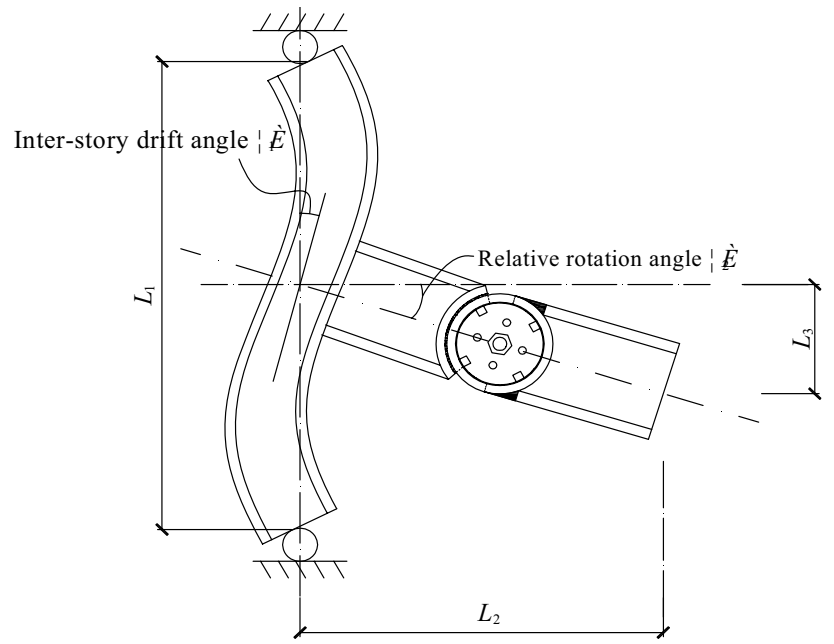

Fig. 2 Inter-storey drift angle and relative rotation angle

analysis of the yield conditions, when the beam end angle $\theta_{2}$ is greater than the elastic limit of rotation of the $\mathrm{PH}$ joint $[\theta]$, some members of the $\mathrm{PH}$ joint will exhibit plastic deformation: limit bolts will cut out slots as they rotate around the loading rotary bolt, and friction will occur at the interface between the two friction plates and the single connection plate due to the relative rotation $\theta_{2}$ indicated in Fig. 2.

According to the shear action of the bolts, the shear stress is uniformly distributed on the surface of the bolts, so the design capacity of a single ordinary bolt is determined by first calculating its design shear capacity as:

$N_{v}^{\mathrm{b}}=n_{v} \frac{\pi d^{2}}{4} f_{v}^{\mathrm{b}}$,

where $n_{v}$ is the number of shear planes on the bolt, $d$ is the diameter of the bolt, and $f_{v}^{\mathrm{b}}$ is the shear strength of the bolt material.

Then, the bearing capacity of the bolt is calculated using:

$N_{c}^{\mathrm{b}}=d \sum t f_{c}^{\mathrm{b}}$,

where $\sum t$ is the sum of the bearing thicknesses in each force direction and $f_{c}^{\mathrm{b}}$ is the bearing strength of the bolt material.

Finally, the smaller of Eqs. (2) and (3) is selected as the capacity of the bolt as follows:

$N_{\min }^{\mathrm{b}}=\left(N_{v}^{\mathrm{b}}, N_{c}^{\mathrm{b}}\right)_{\min }$.

If the integrity of the bolt hole wall of the connection plate is to be ensured, the design bearing capacity of the component should be greater than the design shear capacity, that is, $N_{c}^{\mathrm{b}}>N_{v}^{\mathrm{b}}$.

The bending moment of the beam section in the elastic limit state controls as it is less than the bending moment

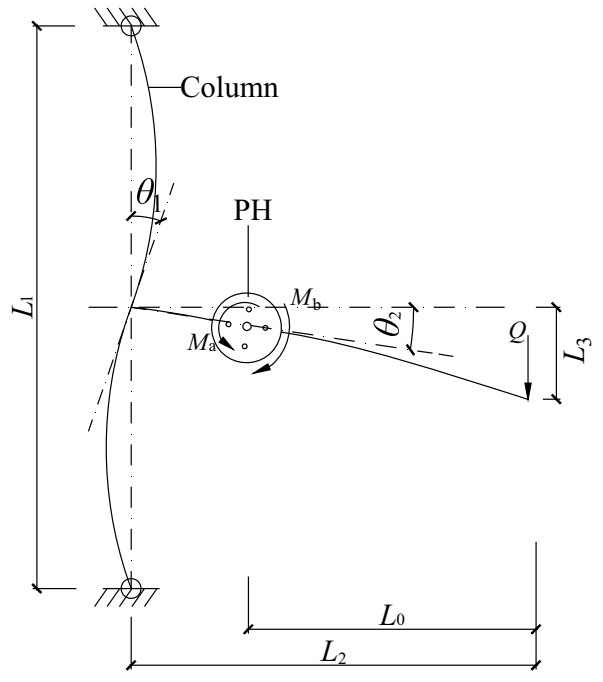

Fig. 3 Mechanical model of the PH joint

at the welded beam-to-column joint and can be determined as follows:

$M_{y}=W_{n x} f_{\mathrm{y}}$,

where $W_{n x}$ is the net section modulus of the beam around the horizontal axis and $f_{\mathrm{y}}$ is the yield strength of the steel at normal temperature.

When the external load on the H-beam's free end is $Q$, the yield moment $M_{a}$ of the PH joint and the bending moment $M_{\mathrm{b}}$ acting on the joint are, respectively:

$M_{a}=4 N_{\min }^{\mathrm{b}} r_{3}$

and

$M_{\mathrm{b}}=Q L_{0}$,

where $r_{3}$ is the distance between the limiting bolts and the loading rotary bolt and $L_{0}$ is the distance between the free end of the beam and the $\mathrm{PH}$ joint.

When $M_{a}>M_{\mathrm{b}}$, the limiting bolts are not sheared and the $\mathrm{PH}$ joint acts as a rigid joint, otherwise the limiting bolts fail in plastic shear and the $\mathrm{PH}$ joint acts a semi-rigid joint. Notably, the yield moment of the PH joint is smaller than the yield moment $M_{\mathrm{y}}$ of the full section of the beam, as shown in Fig. 3.

\subsubsection{Friction Energy Dissipation Analysis of the PH Joint}

When the proposed friction-based $\mathrm{PH}$ joint rotation angle is $\theta$ and $\theta>\theta_{2} \geq[\theta]$, the limiting bolts are sheared, and the friction energy dissipation performance analysis of the node can be calculated as follows. 
For the loading rotary bolt, the clamping force between the connection plates is controlled by the torque tightening method, in which the required torque $M$ is calculated by:

$M=K_{\mathrm{t}} F d$,

where $K_{\mathrm{t}}$ is the tightening force coefficient, $F$ is the applied pre-tightening force, and $d$ is the diameter of the bolt being tightened (in this case, the loading rotary bolt). Thus, the pre-tightening force can be calculated as:

$F=M / K_{\mathrm{t}} d$

The normal force $P$ between the two friction plates and the single connection plate is then determined by:

$P=F / A$,

where $A$ is the area of contact between the two friction plates and the connection plate. So, the friction force between the friction and connection plates is:

$F_{\mathrm{f}}=\alpha f(\theta, r)=\alpha \iint \frac{\mu F}{A} r \mathrm{~d} r \mathrm{~d} \theta=\frac{1}{2} \frac{\alpha \mu F}{A} r^{2} \theta$,

where $\mu$ is the friction coefficient of the material, $r$ is the friction plate radius, $\theta$ is the relative rotation angle of between single connecting plate and circular tube sealing plate, $[\theta]$ is the critical corner value of elasticity, and $\alpha$ is the friction surface influence coefficient (the test-determined value was about 1.3). Now, the friction energy dissipation $M_{\mathrm{f}}$ can be calculated by:

$M_{\mathrm{f}}=\alpha n \iint f(\theta, r) r \mathrm{~d} r \mathrm{~d} \theta$,

where $n$ is the number of friction surfaces.

\subsection{Test Overview}

\subsubsection{Frame Model Design}

A novel friction-based $\mathrm{PH}$ joint was produced at half-scale according to two different relevant standards, FEMA 350 [3] and GB50017-2017 [35], and tested in five model configurations. The general size and setup of the beam-column models tested in this study are shown in Fig. 4, and the specific geometry of the PH joint is given in Fig. 1. According to the weakened joint setting theory in the literature $[3,16]$, the distance from the centre of the PH joint to the face of the column was set at $200 \mathrm{~mm}$, the total length of the PH joint itself was set at $150 \mathrm{~mm}$ (as shown in Fig. 1), and the thickness of connection plates was set at $20 \mathrm{~mm}$. The beam-to-column joints of the frame models were stiffened with steel plates and welded with E43-type rod. This analysis did not consider the influence of weld defects. Both the

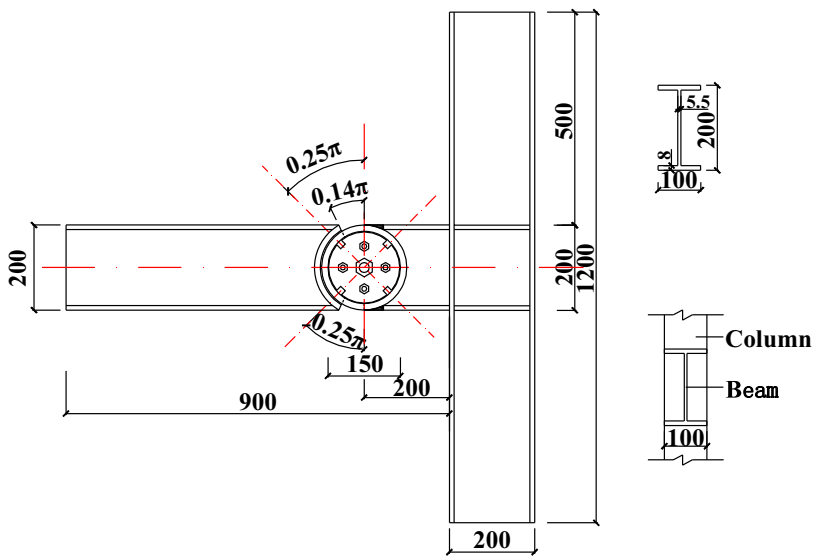

Fig. 4 Frame model and PH joint location (units in mm)

beam and column were fabricated from Q235 hot-rolled HN $200 \times 100$ beams with web and flange thicknesses of $5.5 \mathrm{~mm}$ and $8 \mathrm{~mm}$, respectively.

\subsubsection{PH Joint Design}

The structure of the joint was provided using line cutting technology, so the cutting surface of each part was smooth without incision. The steel beams on each side of the joint were capped with a $15-\mathrm{mm}$-thick circular arc sealing plate and circular tube sealing plate by full penetration groove welding with a bevel angle of $35^{\circ}$, and a middle groove weld was used to attach the single connection plate to the circular arc sealing plate. The circular tube sealing plate was cut from thick steel pipe, and four $15 \mathrm{~mm} \times 15 \mathrm{~mm}$ limit strips were attached on the inside oriented in the length direction of the pipe axis. The circular tube had a single $23 \mathrm{~mm}$ wide connection plate groove cut into it perpendicular to the axis of the tube. Two connection plates corresponding to the size of the circular tube sealing plate were cut from 20 -mm-thick steel plate, and four slots corresponding to the limit strips were set, where the radius $R_{4}$ was $83 \mathrm{~mm}$. At the centre of each connection plate, a 22-mm-diameter loading rotary bolt hole was provided, and four isometrically arranged $10-\mathrm{mm}-$ limiting bolt holes were provided at a distance of $R_{3}$ from the centre hole of $100 \mathrm{~mm}$, as shown in Fig. 1. The loading rotary bolt was a Grade $10.9 \mathrm{M} 22$ high-strength bearing bolt. In order to explore the action of the limiting bolts in the $\mathrm{PH}$ joint and the energy dissipation rule after their shear failure, two types of limiting bolts were evaluated: Grade $4.8 \mathrm{M} 10$ ordinary bolts and Grade $8.8 \mathrm{M} 10$ high-strength bolts. Two types of friction materials were evaluated: a rubber plate (RP) and composite resin plate (CP) with copper wire reinforcement. The structure of the $\mathrm{PH}$ joint is shown in Fig. 1, and the parameters of the five different $\mathrm{PH}$ joint models tested are defined in Table 1. 
Table 1 Test parameters of PH joint models (Grade 0 means no shear bolts)

\begin{tabular}{llllll}
\hline Model conditions & PH-1 & PH-2 & PH-3 & PH-4 & PH-5 \\
\hline Limiting bolt grade & 4.8 & 8.8 & 4.8 & 0 & 0 \\
Friction plate type & RP & RP & CP & RP & CP \\
Load torque (N m) & 250 & 250 & 250 & $375,450,550$ & 550
\end{tabular}

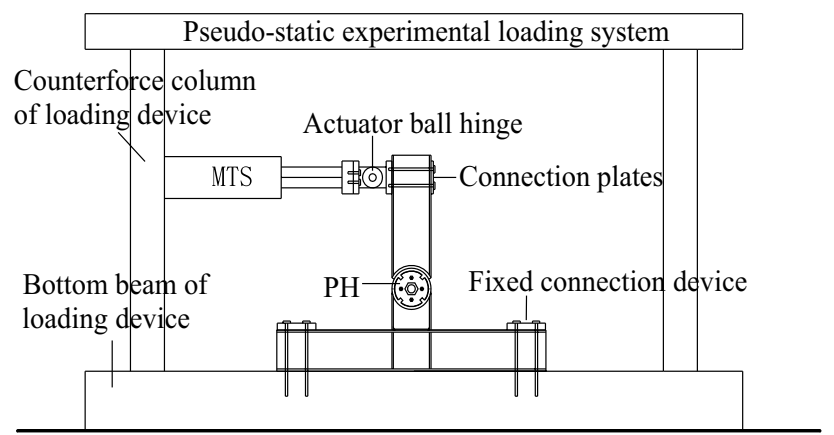

Fig. 5 Schematic of test setup

\subsubsection{Test Setup and Loading System}

The H-beam models were tested in the arrangement, illustrated in Fig. 5, in which the column was horizontally fixed to the test frame bottom beam at each end, and the end of the steel beam was attached to a horizontal MTS LSWEB$25 \mathrm{~T}$ actuator using plates connected by threaded rods. The actuator had a load range of $\pm 250 \mathrm{kN}$, stroke of $\pm 125 \mathrm{~mm}$, and system accuracy of $1 \%$, and was used to apply a cyclic reciprocating displacement load to the frame model. Beam end control point test data were collected and stored by the control system of the LSWEB-250 $\mathrm{kN}$ actuator [36]. The loading rotary bolt was tightened using a torque wrench with a range of $100-550 \mathrm{~N} \mathrm{~m}$. A photograph of the loading device is shown in Fig. 6.

In accordance with the AISC seismic code [37], loading was controlled by variable amplitude displacement to ensure a lateral displacement angle between frame stories. During the test, $\theta_{2}$ at the beam end of the beam-to-column connection, approximated by the ratio of beam end displacement to beam length, was used in place of the lateral displacement between frame stories, $\theta_{1}$, as discussed in Sect. 2.3.1 and shown in Fig. 2. The loading displacement amplitude, cycle times, and corresponding lateral displacement angle between levels are shown in Table 2 and Fig. 7. During the test loading, each cycle took 5 min to apply, and the entire test took about $2.5 \mathrm{~h}$ to complete from initial loading to the end.

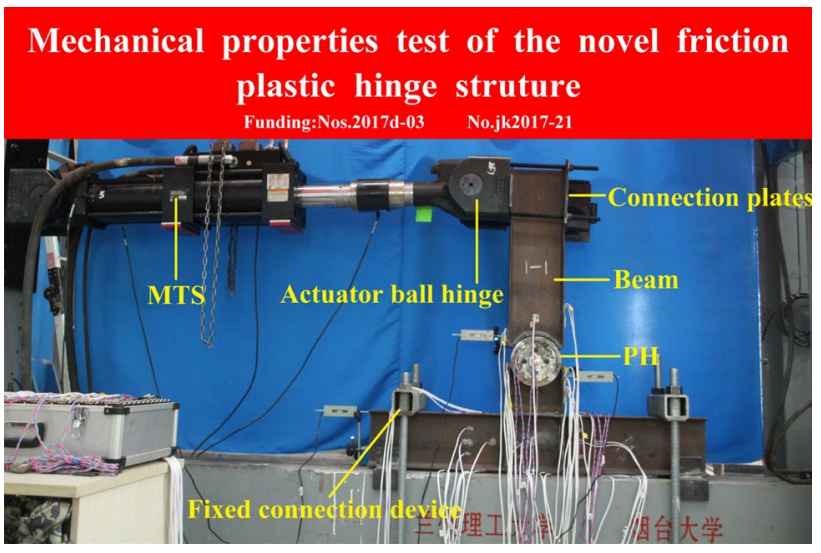

Fig. 6 Photograph of test setup

Table 2 Loading history

\begin{tabular}{llll}
\hline Load level & $\begin{array}{l}\text { Displacement } \\
\text { amplitude }(\mathrm{mm})\end{array}$ & Cycle count & $\begin{array}{l}\text { Inter-storey } \\
\text { drift angle } \\
(\mathrm{rad})\end{array}$ \\
\hline 1 & \pm 2.7 & 3 & 0.0038 \\
2 & \pm 3.5 & 3 & 0.0050 \\
3 & \pm 5.3 & 3 & 0.0075 \\
4 & \pm 7.0 & 2 & 0.0100 \\
5 & \pm 10.5 & 2 & 0.0150 \\
6 & \pm 14.0 & 2 & 0.0200 \\
7 & \pm 21.0 & 2 & 0.0300 \\
8 & \pm 28.0 & 2 & 0.0400 \\
9 & \pm 35.0 & 2 & 0.0500 \\
10 & \pm 50.0 & 2 & 0.0700 \\
11 & \pm 70.0 & 2 & 0.1000 \\
12 & \pm 90.0 & 3 & - \\
13 & \pm 110.0 & 3 & - \\
\hline
\end{tabular}

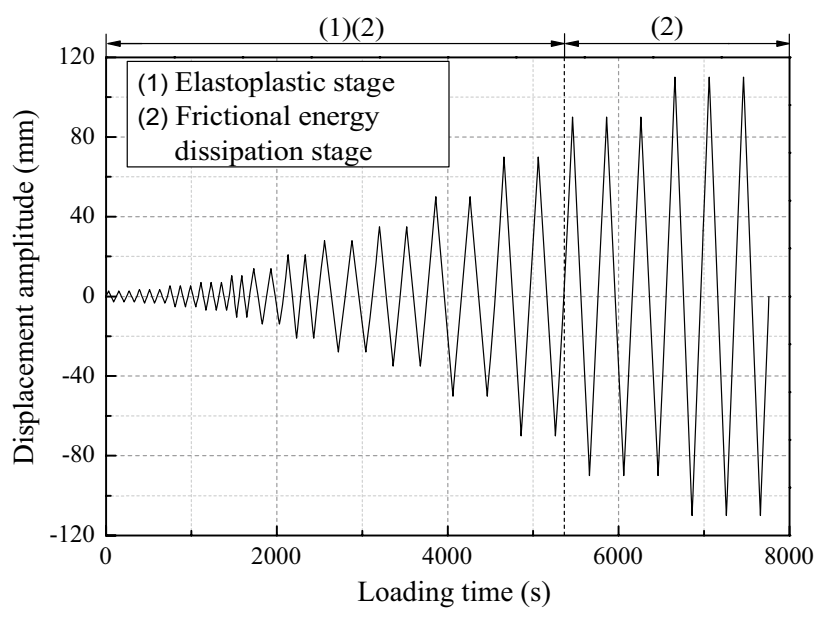

Fig. 7 Load-displacement amplitude curve 


\section{Results}

For models PH-1 and PH-3, which were chosen as exemplary of the $\mathrm{PH}$ joint behaviour, the four limiting bolts were Grade 4.8 M10 ordinary bolts, the tightening torque of the loading rotary bolt was $250 \mathrm{~N} \mathrm{~m}$, and the friction materials were rubber plates and composite resin plates, respectively. After the test, the composite resin friction plates of $\mathrm{PH}-3$ were broken due to the action of the limiting bolts (as in Fig. 8e), while the rubber friction plates of PH-1 exhibited only surface wear (as in Fig. 8b). The limiting bolts of both models exhibited clear shear failure as they were cut into three parts with relatively flat shear surfaces, as shown in Fig. 8a. The other parts of PH-1 exhibited no evident damage.

For PH-2, the four limiting bolts were Grade 8.8 M10 high-strength bolts, the loading torque of the loading rotary bolt was $250 \mathrm{~N} \mathrm{~m}$, and the friction materials were rubber plates. After the test, the limiting bolts had been deformed by shear but not destroyed. The limiting bolt holes in each connection plate exhibited plastic deformation and elongation, as shown in Fig. 8c, d, while components such as the beam and column were not damaged. Note that $\mathrm{PH}-2$ failed in generally the same manner as the $\mathrm{PH}-1$ model, shown in Fig. 9.

Generally, the surfaces of the rubber friction plates, shown in Fig. 8b, were obviously worn, exhibiting a loss of about $6.37 \%$, while the composite resin friction plate surfaces, shown in Fig. 8e, were not obviously worn, exhibiting a loss of about $1.03 \%$.

\section{Analysis and Discussion}

\subsection{Load Capacity of Test Model}

Under the displacement load applied to the end of the test model beam, the limiting shears of the Grade 4.8 ordinary bolts and Grade 8.8 high-strength bolts were selected as the working conditions of test models $\mathrm{PH}-1$ and $\mathrm{PH}-2$, respectively. For this evaluation, only the rubber friction plates

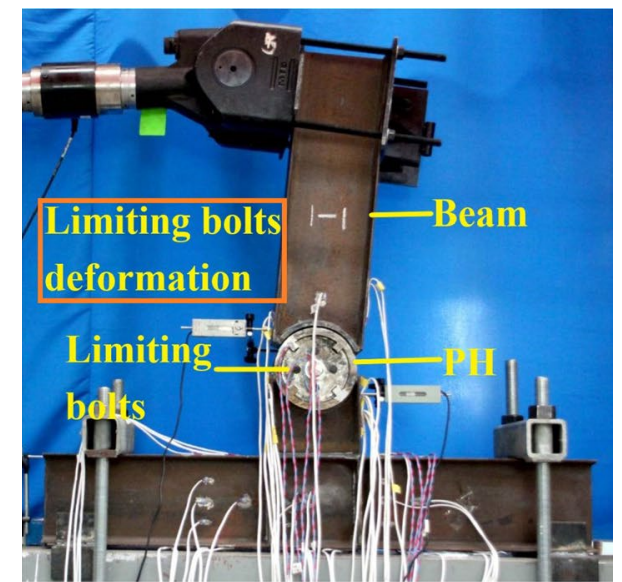

(a)

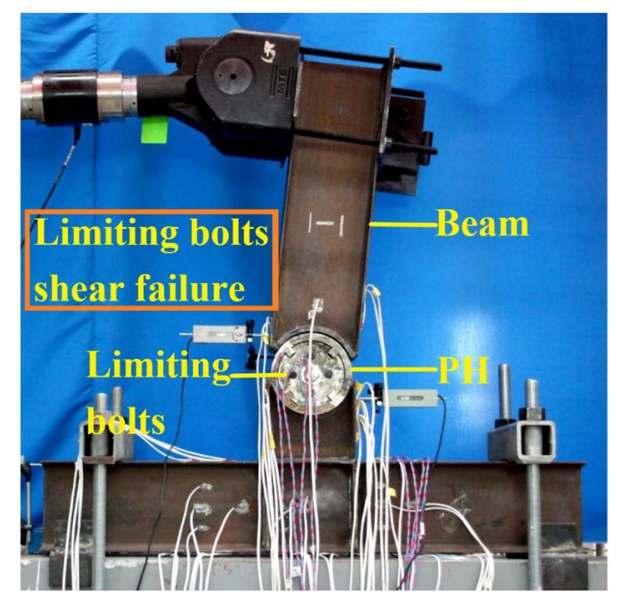

(b)

Fig. 9 Typical failure state of tested models: a elastic plastic deformation stage of limiting bolts; $\mathbf{b}$ shear failure stage of limiting bolts

were considered, and the tightening torque of the loading rotary bolt was $250 \mathrm{~N} \mathrm{~m}$. According to the test results, the influence of actuator deviation when negative displacement was applied was quite large, and $\mathrm{PH}-2$ only exhibited plastic deformation of some of its components. According to the contact relationship between steel and friction material, the sliding friction coefficient $\mu$ was calculated by test theory to be 0.45 . Therefore, only the ultimate load capacity of the

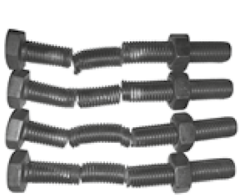

(a)

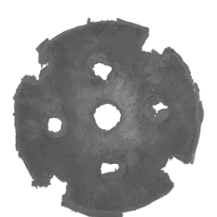

(b)

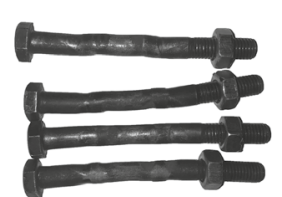

(c)

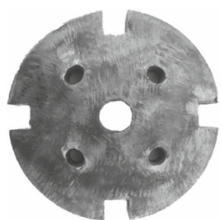

(d)

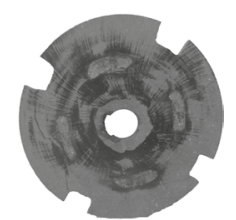

(e)

Fig. 8 Failure characteristics of various components: a Grade 4.8 M10 bolts (PH-1); b rubber friction plates (PH-4, 550 N m); c Grade 8.8 M10 bolts (PH-2); d double connection plates (PH-2); e composite resin friction plates (PH-5, $550 \mathrm{~N} \mathrm{~m}$ ) 
test model under positive displacement loading is compared in Table 3 with the results of the theoretical calculation described in Sect. 2.3.2, showing that the theoretical results were in good agreement with the experimental results. The applied loads, $Q_{e}$ and $Q_{t}$, shown in Table 3 can be related to the moment in the beam using Eq. (7). Thus, the theoretical analysis of the load capacity and the experimental load-displacement curves can be considered reliable.

Note that under the test conditions and given the mechanical properties of the structure, the strain in the structural beam and column was found to be relatively small, so the stress and strain behaviours were not obvious. This suggested that only the elastic deformation state was present throughout the tests, having little impact on the friction energy dissipation effect of the structure. Accordingly, only a friction energy dissipation analysis was conducted to evaluate the cyclic loading test results.

\subsection{Hysteresis Characteristics}

\subsubsection{Experimental Study of Whole-Process Loading}

Figure 10 shows the load-displacement hysteresis curves of the beam end of the test models. The entire process of the loading test included the full process of bolt shear and development of pure friction in the $\mathrm{PH}$ joint. As can be seen from Fig. 10a, b, for PH-1 with Grade 4.8 ordinary limiting bolts and rubber and composite resin friction plates, respectively, two stages of energy dissipation behaviour develop with the ongoing application of cyclic loading. In the first stage, the energy dissipation is manifested by a transition from an $\mathrm{S}$-shaped and relatively full hysteretic curve to a Z-shaped curve, mainly dictated by the deformation energy dissipation of the elastoplastic shear of the limiting bolts, which constitutes a stable energy dissipation trend. In the second stage of energy dissipation, the shear failure of the limiting bolts has already occurred and thus the limiting bolts have stopped working; still, when the displacement reached $90 \mathrm{~mm}$, the hysteresis curve exhibited friction energy dissipation and thus good energy dissipation performance. However, when loaded with negative displacement, the structure exhibited an abrupt change in the curve due to the influence of the ball hinge of the actuator connection under the applied torque. By comparing the curves of $\mathrm{PH}-1$ and $\mathrm{PH}-3$, it can be concluded that the hysteresis effect is basically consistent regardless of friction material used.

Table 3 Comparison of calculated and test-determined model load capacity

\begin{tabular}{llll}
\hline Model & Calculated $Q_{e}(\mathrm{kN})$ & Test $Q_{t}(\mathrm{kN})$ & $Q_{e} / Q_{t}$ \\
\hline PH-1 & 15.84 & 17.41 & 0.91 \\
PH-2 & 21.33 & 23.05 & 0.93 \\
\hline
\end{tabular}

It can be seen from Fig. 10c, $d$ that for PH-2 with Grade 8.8 high-strength limiting bolts and rubber friction plates, with the ongoing change in applied displacement, the load-displacement curve of the structure shows a certain slip effect. The shape of the hysteresis curve is anti-S-shaped at first and then tends to be Z-shaped and relatively full. The interaction between the connection plate and the limiting bolts caused the bolt holes to undergo elastic-plastic deformation and elongate, resulting in energy dissipation. The high-strength limiting bolts also experienced elastoplastic shear deformation, further dissipating energy. In this test, the plastic deformation energy dissipation of the $\mathrm{PH}$ plate material was the main mode of energy dissipation, the limiting bolts did not fail, and the structure did not reach its ultimate capacity at the maximum applied displacement. Accordingly, high-strength bolts are not suitable for use as limiting bolts in this PH design. Comparing Fig. 10a with c, the grade of the limiting bolts also affected the shape of the hysteresis curve and the load capacity.

\subsubsection{Experimental Study of Pure Friction Loading}

According to Fig. 10e, f, when the specimen was only subjected to a friction energy dissipation performance analysis without considering the effect of the limiting bolts and with either rubber or composite resin friction plates, at a maximum displacement of $\pm 90 \mathrm{~mm}$, the hysteresis curves show the same basic characteristics and exhibit the same structure under negative load displacement, indicating good energy dissipation. Under a consistent rotary bolt tightening torque of $550 \mathrm{~N} \mathrm{~m}$, the energy dissipation performance when using the composite resin friction plates was a little better than that using the rubber friction plates, as can be seen in Fig. 10e. When the friction energy dissipation performance of only the rubber friction plates is analysed under rotary loading bolt tightening torques of $375 \mathrm{~N} \mathrm{~m}, 450 \mathrm{~N} \mathrm{~m}$, and $550 \mathrm{~N} \mathrm{~m}$, the area of the hysteresis loops can be observed to increase with the increase in tightening torque, as does the hysteresis energy dissipation performance, as shown in Fig. $10 \mathrm{f}$.

\subsection{Skeleton Curves and Stiffness Characteristics}

Figure 11 shows the skeleton curves of joint models PH-1 and $\mathrm{PH}-2$, in which it can be seen that PH-2 with Grade 8.8 high-strength limiting bolts exhibits superior load capacity and better ductility. When considering the elastic-plastic deformation performance of the PH components, the connection plates reach yield deformation before the highstrength limiting bolts, and thus, the load capacity and ductility of the structure are higher. The ultimate capacity of PH-1 with Grade 4.8 ordinary limiting bolts is smaller, and the limiting bolts reach their shear yield limit earlier, so the ductility of this specimen is relatively poor. However, some 


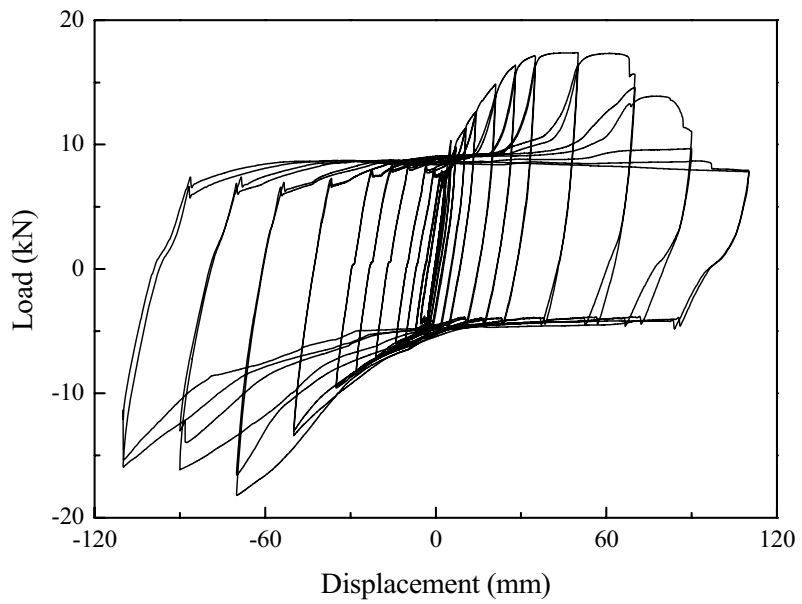

(a)

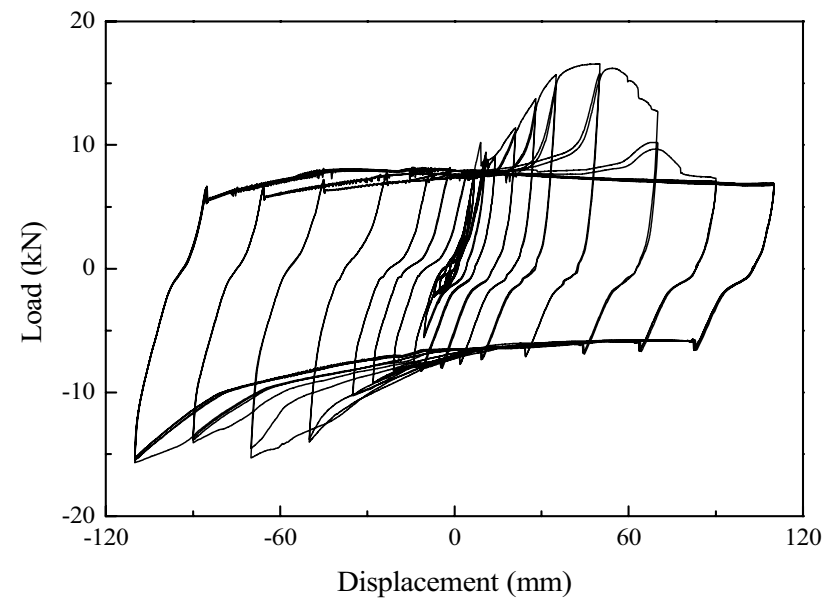

(b)

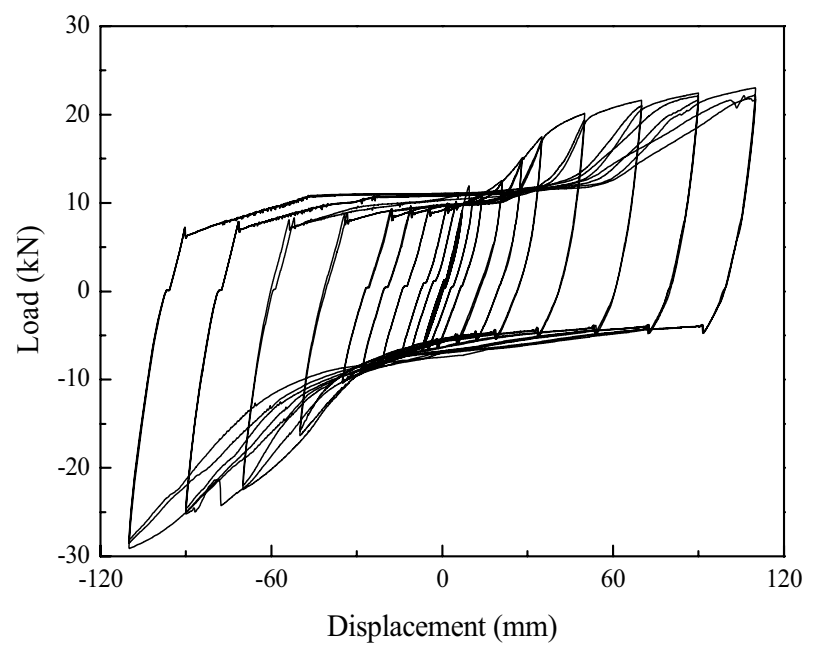

(c)

Fig. 10 Beam end load-displacement curves of test models: a PH-1, Grade 4.8 bolts, rubber friction plates; $\mathbf{b}$ PH-3, Grade 4.8 bolts, composite resin friction plates; c $\mathrm{PH}-2$, Grade 8.8 bolts, rubber friction plates; d PH-1 and PH-2 comparison of bolt grades, rubber friction

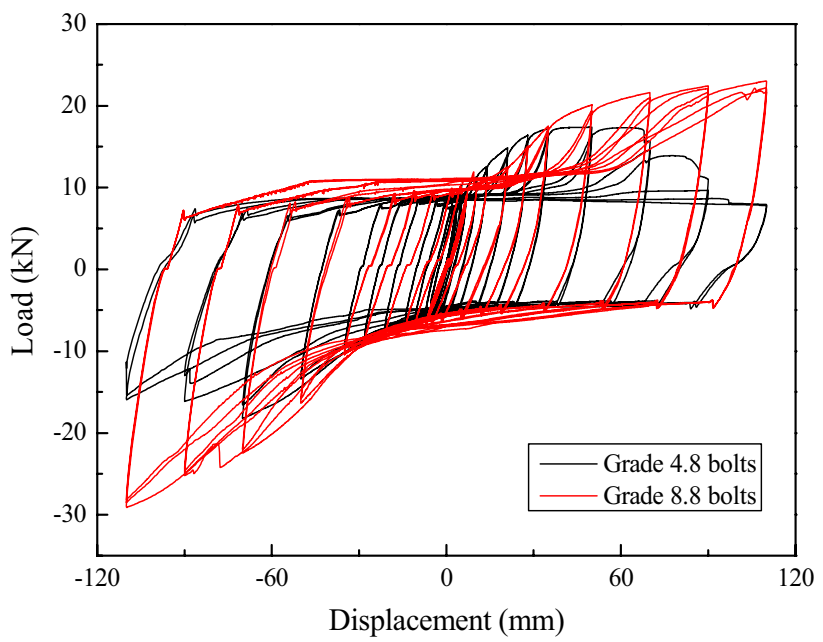

(d)

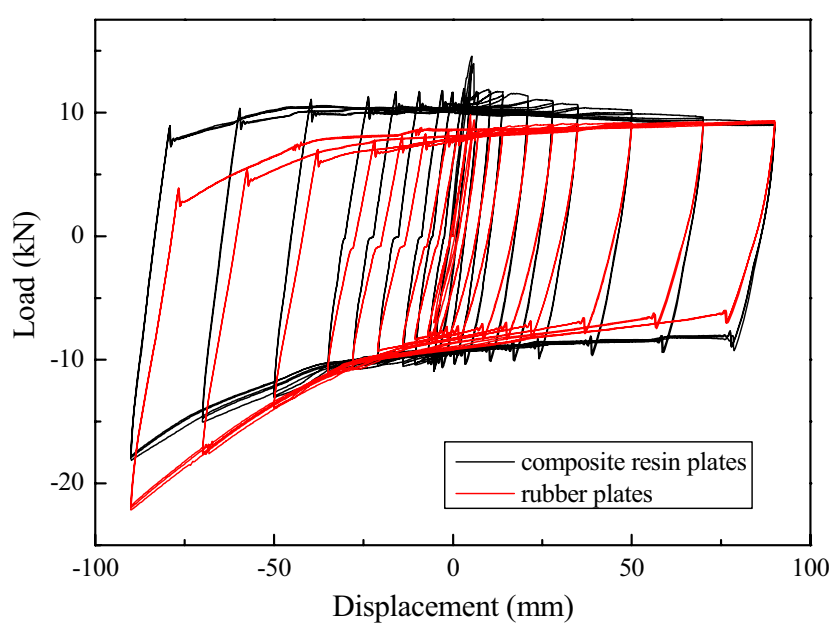

(e)

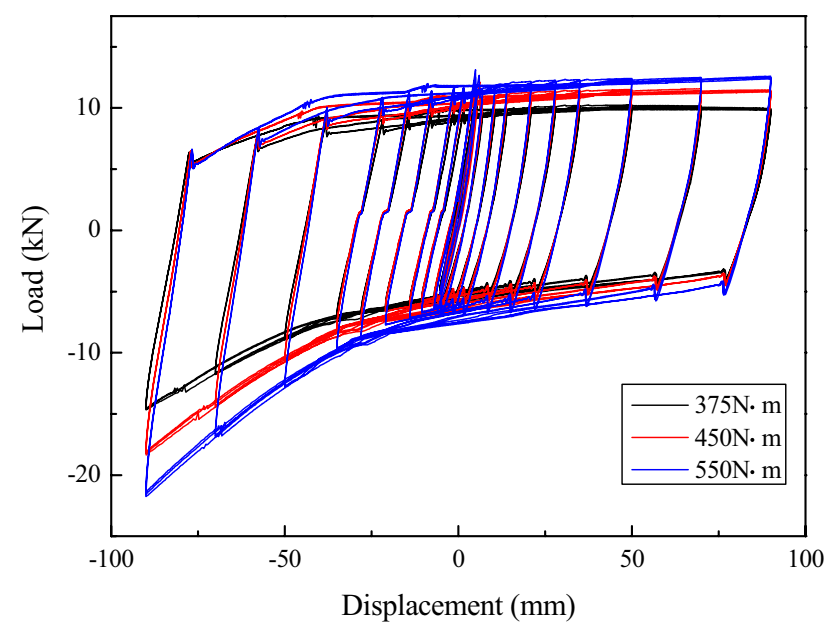

(f)

plates; e PH-4 and PH-5 with no shear bolts, comparison of friction plate material, loading rotary bolt tightening torque $550 \mathrm{~N} \mathrm{~m}$; f PH-4 with no shear bolts, three different loading rotary bolt tightening torques, rubber friction plates 


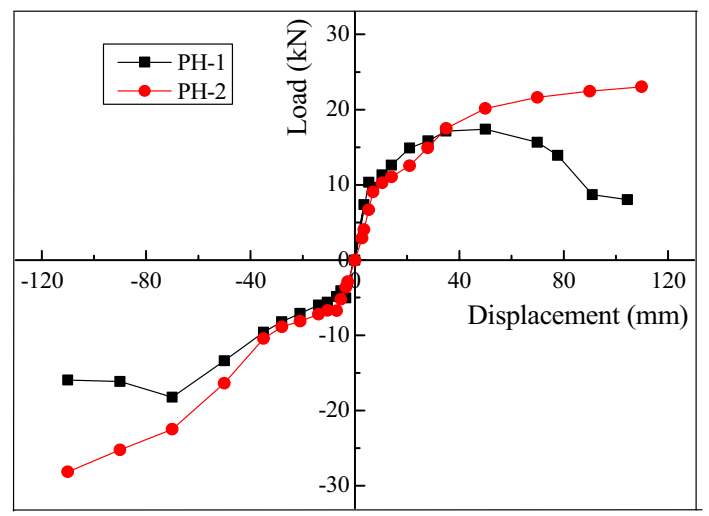

Fig. 11 Skeleton curves of specimens

parts of PH-2 were damaged, while the failure of the limiting bolts in $\mathrm{PH}-1$ prevented such damage. Thus, the use of high-strength bolts in $\mathrm{PH}-2$ did not meet the design requirements that the PH be easily repairable. Overall, all models exhibited a large plastic rotation angle exceeding $0.05 \mathrm{rad}$, which satisfies the requirement that the plastic bending angle of the special bending-resistant steel frame connecting beam be greater than $0.03 \mathrm{rad}$.

According to the hysteresis curves of models with Grade 4.8 and Grade 8.8 limiting bolts, shown in Fig. 10a, c, respectively, there is little difference in the stiffness degradation value for cycles with the same amplitude. When loading in the positive displacement direction, the Grade 4.8 limiting bolts of PH-1 suffered shear failure and obvious stiffness degradation, while there was relatively little stiffness degradation of $\mathrm{PH}-2$, which showed no obvious decrease in performance. Due to the influence of the torque applied to the ball hinge of the actuator connection, the stiffness degradation curves of both $\mathrm{PH}-1$ and $\mathrm{PH}-2$ are not clear, but they indicate that the material strength of the connection plates and limiting bolts has an impact on the stiffness degradation of the structure when considering the effects of observed test errors.

\subsection{Ductility Coefficient}

Ductility is an important characteristic in the seismic performance of engineering structures. The ductility of a structure under repeated load reflects the plastic deformation ability of the overall structure or its components without experiencing significant reduction in capacity as they enter the failure stage. The greater the ductility of the structure or component, the stronger its ability to dissipate seismic energy and exhibit inelastic deformation; that is, the better its seismic performance. The ductility of a structure or component is usually measured by the ductility coefficient $\mu_{1}$, which refers to the ratio of the ultimate displacement $\delta_{\mathrm{u}}$ to the yield displacement $\delta_{\mathrm{y}}$ of the structure or member; that is, $\mu_{1}=\delta_{\mathrm{u}} / \delta_{\mathrm{y}}$. Accordingly, using the skeleton curves in Fig. 11, the equivalent yield point was determined by approximation based on equal areas [38] and the ultimate and yield displacements were then determined from the geometry of the curve [32]. The ductility coefficients of PH- 1 and $\mathrm{PH}-2$ were about 2.75 and 3.14, respectively, indicating that the seismic performance of the $\mathrm{PH}$ joint was affected by the considered test factors such as the bolt grade, test setup, and load.

\section{Conclusion}

1. The test results showed that the proposed friction-based PH joint exhibits good plastic deformation capacity and energy dissipation performance. In the experiments, all tested specimens achieved a large plastic rotation angle in excess of $0.05 \mathrm{rad}$, meeting the requirements that the plastic rotation angle for a special bending-resistant steel frame connecting beam be greater than $0.03 \mathrm{rad}$. The ductility coefficients of models $\mathrm{PH}-1$ and $\mathrm{PH}-2$ were about 2.75 and 3.14, respectively. Notably, results indicate that the ductility can be improved by adjusting the influencing factors of the test, including the shear bolt strength, the friction material performance, and the torque of the loading rotary bolt. The test results show that the intended plastic hinge can be established when the proposed PH joint is set at the structure node under the action of low cyclic reciprocating displacement. This can help to avoid the brittle failure of the weld between the beam and column caused by the development of beam root stress and is beneficial to the design concept of providing plastic hinge displacement outside of the column.

2. The main failure forms of the proposed friction-based PH joint under the test conditions were as follows: the beam was weakened at the location of the $\mathrm{PH}$, leading to the appearance of an obvious plastic hinge that provided plastic displacement outside the column, and then, the plastic deformation at the $\mathrm{PH}$ joint increased, causing the four limiting bolts to fail in shear or the bolt holes of the connection plates to undergo plastic deformation, at which time the friction material exhibited certain wear. When using high-strength limiting bolts, plastic failure of the connection plates was observed, which is unsuitable behaviour for a PH joint that must be easily repairable. Therefore, the structural material strength, performance of the limiting bolts, and friction material of the $\mathrm{PH}$ all affect the behaviour of the proposed $\mathrm{PH}$ joint.

3. In the design of the PH-containing structure, reasonable parameters should be set according to the distribution of the bending moment. This can be accomplished by adjusting the distance from the $\mathrm{PH}$ joint to the column, 
the distance from the limiting bolts to the centre of rotation, the size and performance of the limiting bolts, the characteristics of the friction material, etc. To ensure the quality and continuity of the welds in the PH joint, the design shear capacity of the limiting bolts should be set to less than the design capacity of the connection plates, and the yield moment of the $\mathrm{PH}, M_{a}$, should be set smaller than the yield moment of the full section of the beam $M_{y}$. The influence of flaws in the connection between the components of the joint on the moment capacity, ductility, and hysteresis energy dissipation should also be fully considered.

4. The experimental study and theoretical analysis of the proposed friction-based $\mathrm{PH}$ joint indicate that it can effectively realize the fixed-point displacement of a plastic hinge; the best $\mathrm{PH}$ configuration, which only exhibited plastic failure of the limiting bolts and friction material wear, was able to provide the predicted energy dissipation and good hysteretic energy dissipation performance. After the test, neither the beam nor the column was damaged, and only the disposable parts of the $\mathrm{PH}$ member required replacement, achieving the goal of rapid repair after an earthquake.

Funding Funding was provided by the Achievements Transformation Project of the Gansu Provincial Education Department (Grant No. 2017d-03), the Scientific and Technological Project of the Gansu Provincial Construction Department (Grant No. jk2017-21), the National Natural Science Foundation of China (Grant No. 51968043).

\section{Compliance with Ethical Standards}

Conflict of interest The authors declare that they have no conflict of interest.

Open Access This article is distributed under the terms of the Creative Commons Attribution 4.0 International License (http://creativecommons.org/licenses/by/4.0/), which permits unrestricted use, distribution, and reproduction in any medium, provided you give appropriate credit to the original author(s) and the source, provide a link to the Creative Commons license, and indicate if changes were made.

\section{References}

1. Ru, J.P.; Yang, N.; Yang, Q.S.: A review on the seismic performance of steel moment connections with reduced beam sections. Eng. Mech. 21(1), 61-66 (2004). (in Chinese)

2. Hoang, V.L.; Dang, H.N.; Jaspart, J.P.; Demonceau, J.F.: An overview of the plastic-hinge analysis of 3D steel frames. Asia Pac. J. Comput. Eng. 2(1), 4 (2015)

3. FEMA-350: Recommended Seismic Design Criteria for New Steel Moment-Frame Buildings. Federal Emergency Management Agency, Washington (2000)

4. Englehardt, M.D.: Design of reduced beam section moment connections. In: Proceedings-1999 North American Steel
Construction Conference, Chicago, 1998, pp. 1-29. American Institute of Steel Construction (1998)

5. Chen, S.J.; Tsao, Y.C.; Chao, Y.C.: Enhancement of ductility of existing seismic steel moment connections. J. Struct. Eng. 127(5), 538-545 (2001)

6. Lee, C.H.; Jung, J.H.; Oh, M.H.; Koo, E.S.: Cyclic seismic testing of steel moment connections reinforced with welded straight haunch. Eng. Struct. 25(14), 1743-1753 (2003)

7. Marante, M.E.; Picón, R.; Flórez-López, J.: Analysis of localization in frame members with plastic hinges. Int. J. Solids Struct. 41(14), 3961-3975 (2004)

8. Peng, B.H.H.; Macrae, G.A.; Walpole, W.R.; Moss, P.; Dhakal, R.P.; Clifton, C.; Hyland, C.: Location of plastic hinges in axially loaded steel members. J. Constr. Steel Res. 64(3), 344-351 (2008)

9. Yan, Z.; Au, F.: Nonlinear dynamic analysis of frames with plastic hinges at arbitrary locations. Struct. Des. Tall Spec. Build. 19(7), 778-801 (2010)

10. Liu, Y.J.; Wang, Y.: Seismic performance experimental research on haunch connection of steel frame. World Earthq. Eng. 32(01), 65-74 (2016). (in Chinese)

11. Huo, J.; Wang, H.; Wang, N.; Zhang, S.: Experimental study on impact behavior of strengthened beam-column connections of steel frames. J. Build. Struct. 37(06), 131-140 (2016). (in Chinese)

12. Oh, K.; Lee, K.; Chen, L.; Hong, S.B.; Yang, Y.: Seismic performance evaluation of weak axis column-tree moment connections with reduced beam section. J. Constr. Steel Res. 105, 28-38 (2015)

13. Lee, S.C.; Yoo, C.H.: Strength of plate girder web panels under pure shear. J. Struct. Eng. 124(2), 184-194 (1998)

14. Lee, S.C.; Lee, D.S.; Yoo, C.H.: Ultimate shear strength of long web panels. J. Constr. Steel Res. 64(12), 1357-1365 (2009)

15. Wang, X.L.; Shen, S.Z.; Yin, Z.Z.; Li, Q.F.: Experimental research on mechanical behavior of beam-column connections with openings on beam webs in steel frames. Eng. Mech. 23(06), 65-76 (2006). (in Chinese)

16. Cai, Y.Y.: Design of steel frame beam-column connection considering plastic hinge outward displacement. Build. Struct. 34(2), 3-5 (2004). (in Chinese)

17. Xu, Y.L.; Lu, L.F.; Li, C.C.: Influencing factor analysis on seismic performance of I-shaped column weak-axis with reduced beam section in frame side joint. J. Disaster Prev. Mitig. Eng. 37(04), 656-664 (2017). (in Chinese)

18. Xie, G.J.; Wang, W.Z.; Zhao, Y.H.; Chen, F.Y.: Low-cycle reversed loading tests on inner diaphragm joints of $\mathrm{H}$-style steel beam-square steel tubular column with circular enlarged juncture near butt weld and opening holes at beam flanges. Build. Struct. 43(21), 14-17 (2013). (in Chinese)

19. Wang, Y.; Li, Q.G.; Dong, J.L.; Zhuang, P.: Experimental study on seismic behavior of space steel frame with reduced beam section connections. J. Build. Struct. 37(S1), 192-200 (2016). (in Chinese)

20. Llanes-Tizoc, M.D.; Reyes-Salazar, A.; Bojorquez, E.; Bojorquez, J.; Lopez-Barraza, A.; Rivera-Salas, J.L.; Gaxiola-Camacho, J.R.: Local, story, and global ductility evaluation for complex 2D steel buildings: Pushover and dynamic analysis. Appl. Sci. 9(1), 200 (2019)

21. Suizi, J.; Wanlin, C.; Zibin, L.; Wei, D.; Yingnan, S.: Experimental study on a prefabricated lightweight concrete-filled steel tubular framework composite slab structure subjected to reversed cyclic loading. Appl. Sci. 9(6), 1264 (2019) 
22. Yang, W.; Yan, R.; Suo, Y.; Zhang, G.; Huang, B.: Experimental study on hysteretic behavior of the overlapped k-joints with concrete filled in chord. Appl. Sci. 9(7), 1456 (2019)

23. Chen, T.G.; Zhao, G.J.: The mechanism research of steel frame ductility node plastic hinge relocation. Steel Constr. 29(12), 25-31 (2014). (in Chinese)

24. Goswami, R.; Murty, C.V.R.: Externally reinforced welded I-beam-to-box-column seismic connection. J. Eng. Mech. 136(1), 23-30 (2010)

25. Lee, C.H.; Jeon, S.W.; Kim, J.H.; Uang, C.M.: Effects of panel zone strength and beam web connection method on seismic performance of reduced beam section steel moment connections. J. Struct. Eng. 131(12), 1854-1865 (2005)

26. Kanyilmaz, A.; Muhaxheri, M.; Castiglioni, C.: Influence of repairable bolted dissipative beam splices (structural fuses) on reducing the seismic vulnerability of steel-concrete composite frames. Soil Dyn. Earthq. Eng. 119(4), 281-298 (2019)

27. Valente, M.; Castiglioni, C.A.; Kanyilmaz, A.: Welded fuses for dissipative beam-to-column connections of composite steel frames: numerical analyses. J. Constr. Steel Res. 128(1), 498-511 (2017)

28. Valente, M.; Castiglioni, C.A.; Kanyilmaz, A.: Numerical investigations of repairable dissipative bolted fuses for earthquake resistant composite steel frames. Eng. Struct. 131(1), 275-292 (2017)

29. Dougka, G.; Dimakogianni, D.; Vayas, I.: Innovative energy dissipation systems (FUSEIS 1-1) - experimental analysis. J. Constr. Steel Res. 96(5), 69-80 (2014)
30. Li, X.D.; Wang, Q.T.; Zhao, J.: Study on energy dissipation test of friction pendulum isolation bearing based on friction material. Sichuan Build. Sci. 43(05), 90-93 (2017). (in Chinese)

31. Hong, G.X.: Ceramic friction material for automotive braking system. Automob. Parts 2, 62-64 (2015). (in Chinese)

32. Li, X.D.; Wang, Q.T.; Ma, N.Y.; Shen, Y.H.; Zhao, Y.; Meng, Q.; Kang, Y.K.: A frictional plastic hinge for nondestructive structure. Gansu: CN108204040A, 26 June 2018 (2018) (in Chinese)

33. Zhou, X.H.; Zhou, Q.S.: Calculation of internal forces and drift of staggered truss structure under lateral loads. J. Build. Struct. 25(04), 66-71 (2004). (in Chinese)

34. Tsavdaridis, K.D.; Papadopoulos, T.A.: FE parametric study of RWS beam-to-column bolted connections with cellular beams. J. Constr. Steel Res. 116, 92-113 (2016)

35. GB50017-2017: Standard for Design of Steel Structures. China Architecture \& Building Press, Beijing (2018). (in Chinese)

36. Ma, Y.; Ji, Q.; Chen, S.; Song, G.: An experimental study of ultralow power wireless sensor-based autonomous energy harvesting system. J. Renew. Sustain. Energy 9(5), 054702 (2017)

37. ANSI/AISC 341-05: Recommended Provisions for Structural Steel Buildings. American Institute of Steel Construction, Chicago (2005)

38. Li, Z.X.: Experimental Theory and Technology of Engineering Structure. Tianjin University Press, Tianjin (2004). (in Chinese) 